\title{
Dossier: John Dewey y Albert C. Barnes: filosofía, educación y estética
}

Este Dossier está compuesto por dos textos: la traducción de la reseña que Dewey escribe en 1926 sobre el libro de Albert C. Barnes (1925) The Art in Painting, titulada "Art in Education - Education in Art", en primer lugar; un artículo que escribimos (Educación y Arte. Acerca de John Dewey) que toma parte de la temática planteada en la reseña interpretándola a la luz de la filosofía del ilustre pragmatista clásico, en segundo lugar.

John Dewey nace en 1859 en Vermont y fallece en New York en 1952. En su extensa vida de 92 años publica una colosal cantidad de páginas sobre las más diversas temáticas filosóficas: desde epistemología y metafísica hasta filosofía práctica. Si uno observa su producción intelectual desde sus inicios hasta 1920, sin embargo, se nota el innegable predominio de cuatro temas: la pedagogía y la filosofía de la educación indudablemente son los temas centrales para Dewey en ese período (siendo Democracia y Educación 1916, su obra más conocida e influyente); a la psicología y a la filosofía de la psicología le dedica varios textos (Psychology 1887, The Reflex Arc Concept in Psychology 1896, The Psychology of Effort 1897, entre otros); escribe, además, sobre teoría del conocimiento (Is Logic a Dualistic Science? 1890 y The Logic of Verification 1891) y, finalmente, también sobre filosofía moral (Ethics 1908 y The Influence of Darwin on Philosophy 1910).

Casi inadvertido pasa hasta 1920, en tanto, uno de los tópicos que quizás es uno de los más relevantes desde esa fecha: la estética. Solo encontramos breves trabajos publicados sobre esta temática en ese período: Poetry and Philosophy 1890, A History of Aesthetics by Bernard Bosanquet 1893 y The Aesthetic Element in Education 
1897. Desde 1920, en cambio, su interés en la temática lo llevará a publicar uno de sus libros más notables en la década del 30: (1934) Art as Experience. ¿Por qué hacemos hincapié en ese año? Ante la propuesta que Barnes le hace en una carta de dictar un seminario sobre estética, Dewey le responde en enero de 1920 lo siguiente:

Me interesó tu sugerencia sobre un seminario de estética. Pero no puedo involucrarme en eso. Siempre he evitado la estética, el por qué no lo sé.... Y ahora tengo una repulsión bastante firme en contra de toda la discusión estética. Me hace sentir precisamente como se siente el hombre de inteligencia promedio acerca de toda la discusión filosófica (Dewey, 2008 [1920]). Traducción nuestra.

Dewey, que estaba ya en su etapa de madurez con 61 años, reconoce su casi completa ignorancia en el campo estético. La pregunta que surge entonces es ¿Qué lo lleva desde ese desinterés o esa ignorancia de 1920 a la maestría de 1931 (cuando dicta en Harvard las conferencias en honor a William James que son la base del libro) o 1934 (cuando publica Art as Experience)? Esta pregunta puede ser respondida a partir de tomar en consideración tres partes relacionadas: en primer lugar, el Dewey sexagenario redefine su concepción de estética, esto es, la trae del mundo etéreo al mundo terrenal (véase el capítulo segundo de Art as Experience) volviéndola un asunto de interés para investigar desde su concepción filosófica. En otros términos: Dewey no se interesó por la estética hasta entonces porque tenía una visión equivocada de su naturaleza, esto es, la consideraba como mera contemplación. En segundo lugar, la influencia que ejerce Albert C. Barnes sobre su filosofía (a partir de sus escritos, pero también a partir del profuso intercambio epistolar que tienen y sus conversaciones), particularmente su influencia para la transformación de la concepción de arte y de experiencia estética del gran pragmatista clásico. Este aspecto ha sido subrayado, entre otros, por Richard Westbrook: "Si bien la estética de Dewey se diferenciaba en muchos aspectos del formalismo riguroso de Barnes, nadie hizo más que Barnes para ayudarlo a entender el carácter de la experiencia estética $[\operatorname{artful}]$ que convertía la vida en algo más digno para ser vivido (Westbrook, 1993: 390). Traducción nuestra. 
En tercer lugar, la voluntad de superar ciertos malentendidos alrededor de sus primeros esfuerzos de acercarse a la estética. Un primer enfoque sistemático de Dewey hacia el arte se encuentra en el capítulo noveno de Experience and Nature (1925), titulado "Experience, Nature and Art", que anticipa varios aspectos profundizados posteriormente en Art as Experience. Esta visión deweyana del arte fue objeto de furibundas críticas, principalmente por parte de Lewis Mumford. Este último sostiene, particularmente en The Golden Day 1926, que Dewey no entendía la esencia del arte debido al instrumentalismo y al utilitarismo de su pragmatismo. La intención de Dewey de superar esas interpretaciones falaces se hace evidente en una carta que envía en 1930 a su amigo Sidney Hook: "Todavía siento el deseo de entrar en un campo que no he tratado sistemáticamente, y el arte y la estética han venido a mí. Una de las razones es la crítica por descuidarlos [a ellos] y a lo consumatorio [consummatory] en general" (Dewey 2008 [1930], traducción nuestra).

Resumiendo, entonces, Dewey cambia su visión de la estética y el arte en la década del veinte y parte de esos cambios son debidos a la influencia de Albert C. Barnes, tal como lo reconoce en el prefacio a Art as Experience:

Con todo, mi gran deuda es con el doctor A. C. Barnes. Ha leído cada uno de los capítulos y las referencias que hay sobre su obra en este libro tan sólo son una pequeña parte de la deuda que tengo con él. He disfrutado del beneficio de sus conversaciones durante varios años, muchas de las cuales fueron en presencia de su colección, sin rival, de pinturas. La influencia de estas conversaciones, junto con la de sus libros, ha sido el factor principal en la formación de mi propio pensamiento sobre la estética. Todo lo que hay de bueno en este volumen se debe más de lo que yo pudiera decir a la gran obra educacional llevada a cabo en la Barnes Foundation. Esta obra, en su calidad de iniciadora, es comparable a la mejor que se haya hecho en cualquier campo, durante la generación presente, sin exceptuar el de la ciencia. Me gustaría pensar que este volumen es una fase de la extensa influencia que está ejerciendo la Fundación (Dewey, 2008 [1934]: 2). Cursiva nuestra. 
En este contexto nuestro dossier pretende dos cosas: en primer lugar, poner al alcance de los lectores hispanoparlantes la traducción de un texto original de Dewey que es clave para entender el desarrollo de su estética: "La educación en el arte - el arte en la educación"; en segundo lugar, y a partir del texto mencionado, mostrar la influencia de Albert C. Barnes en Dewey, tópico fundamental para entender el desarrollo de su estética y casi completamente descuidado en la literatura secundaria.

\author{
Campeotto, Fabio* \\ Viale, Claudio Marcelo**1
}

* CONICET. UNLaR. Argentina.

** CONICET. CIJS. UNC. UNLaR. Argentina.

\footnotetext{
1 Fabio Campeotto es Licenciado en Historia y Conservación de Bienes Culturales e Historia del Arte por la Universidad de Padua. Italia. Actualmente es Becario doctoral del CONICET (Consejo Nacional de Investigaciones Científicas y Técnicas) en la Universidad Nacional de La Rioja. Argentina. Email: fcgumbo@gmal.com. Áreas de interés: estética e historia del arte. Referencias bibliográficas: "El 'baptisterio paleocristiano' de Treviso: reinterpretación de las funciones de un edificio tardo antiguo" en Anuario del Centro de Estudios Históricos “Carlos C.A. Segreti”, en prensa. Marzo 2017.

Claudio Marcelo Viale es Doctor en Filosofía por la Facultad de Filosofía y Humanidades de la Universidad Nacional de Córdoba (Argentina). Actualmente es investigador del CONICET en el Centro de Investigaciones Jurídicas y Sociales (CIJS-UNC) y profesor de grado y posgrado en la Universidad Nacional de La Rioja. Todas de Argentina. Email: cmviale@gmail.com. Referencias bibliográficas: 1. Viale, Claudio Marcelo. "Sola fides at the Core of Varieties: Luther as Religious Genius in William James's Thought". The Pluralist. Vol. 10, No. 1 (Spring 2015), pp. 80-106. Official Journal of the Society for the Advancement of American Philosophy. University of Illinois Press. 2. Viale, Claudio Marcelo. "Voluntarismo y self-surrender en la concepción de religión de William James”. Areté. Revista Peruana de Filosofia. Vol. XXVII, N 2, 2015 pp. 209-223. Pontificia Universidad Católica de Lima.

Dirección postal: Claudio Marcelo Viale. Centro de Investigaciones Jurídicas y Sociales. Caseros 301, Centro, X5000HG, Córdoba, Argentina.
} 